\title{
Lack of evidence for reduced prefrontal cortical serotonin and dopamine efflux after acute tryptophan depletion
}

\author{
Geoffrey van der Plasse • Dorie (T). J. Meerkerk • \\ Cindy K. J. Lieben • Arjan Blokland • \\ Matthijs G. P. Feenstra
}

Received: 11 April 2007 / Accepted: 20 July 2007 / Published online: 23 August 2007

(C) Springer-Verlag 2007

\begin{abstract}
Rationale Acute tryptophan depletion (ATD) is a widely used method to study the role of serotonin (5-HT) in affect and cognition. ATD results in a strong but transient decrease in plasma tryptophan and central 5-HT synthesis and availability. Although its use is widespread, the evidence that the numerous functional effects of ATD are caused by actual changes in 5-HT neuronal release is not very strong. Thus far, decreases in 5-HT efflux (thought to reflect synaptic release) were only reported after chronic tryptophan depletion or when ATD was combined with blockade of 5-HT reuptake.

Objective With the current experiment, we aimed to study the validity of the method of ATD by measuring the extent to which it reduces the efflux of 5-HT (and dopamine) in the prefrontal cortex in the absence of reuptake blockage.
\end{abstract}

G. van der Plasse $(\bowtie) \cdot$ D. (T). J. Meerkerk · M. G. P. Feenstra Netherlands Institute for Neuroscience,

Royal Netherlands Academy of Arts and Sciences,

Meibergdreef 47,

1105 BA Amsterdam ZO, The Netherlands

e-mail: g.van.der.plasse@nin.knaw.nl

G. van der Plasse

Department of Anatomy and Neuroscience,

VU University Medical Center,

Amsterdam, The Netherlands

C. K. J. Lieben

Department of Neuropsychology and Psychiatry,

Brain and Behaviour Insitute, University of Maastricht,

Maastricht, The Netherlands

A. Blokland

Department of Neurocognition, Faculty of Psychology,

University of Maastricht,

Maastricht, The Netherlands
Materials and methods We simultaneously measured in freely moving animals plasma tryptophan via a catheter in the jugular vein and 5-HT and DA efflux in the medial prefrontal cortex through microdialysis after ATD treatment. Results ATD reduced plasma tryptophan to less than $30 \%$ of control, without affecting 5-HT or DA efflux in the prefrontal cortex, indicating that even strong reductions of plasma tryptophan do not necessarily result in decreases in central 5-HT efflux.

Conclusion The present experiment showed that reductions in plasma tryptophan, similar to values associated with behavioural effects, do not necessarily reduce 5-HT efflux and suggest that the cognitive and behavioural effects of ATD may not be (exclusively) due to alterations in 5-HT release.

Keywords Medial prefrontal cortex · Tryptophan . Microdialysis · Serotonin (5-HT) · Dopamine (DA)

\section{Introduction}

A widely applied method for the study of the role of serotonin (5-HT) in cognition and affective processing is acute tryptophan depletion (ATD; Biggio et al. 1974; Fadda et al. 2000b; Fadda 2000). Through dietary depletion of the essential amino acid tryptophan, peripheral and central availability of this precursor of serotonin can be rapidly lowered (Biggio et al. 1974; Moja et al. 1989). This, in turn, leads to reduced synthesis of the monoamine 5-HT (Gessa et al. 1974) and reduced central availability of this neurotransmitter (Fadda et al. 2000b; Lieben et al. 2004a).

Since the introduction of this method, ATD has been successfully applied in both human and rodent research and has implicated the serotonergic system in cognition (e.g. memory impairments, reduced attention and increased 
impulsivity) and affective processes (e.g. relapse of depressed patients, mild depressive state, aggression and irritability; Fadda 2000; Riedel et al. 2002). Various studies have, furthermore, reported ATD-induced effects on typical 'prefrontal' tasks, like reversal learning (Rogers et al. 1999; Finger et al. 2007) and intra- and extradimensional set shifting (Park et al. 1994), but also ATD-induced changes in prefrontal cortex (PFC) activity as measured with functional magnetic resonance imaging (Rubia et al. 2005; Allen et al. 2006; Evers et al. 2005).

Recent literature, however, shows that the reported cognitive and behavioural effects of ATD are not always reproducible and suggests that ATD as a method for studying 5-HT depletion is particularly suitable for subpopulations that show a vulnerability to 5-HT dysregulation (Fadda 2000; Booij et al. 2003; Fusar-Poli et al. 2006; Jans et al. 2007). These subgroups include remitted depressed patients (Bremner et al. 1997; Young and Leyton 2002; Neumeister et al. 2004), females (Nishizawa et al. 1997; Schmitt et al. 2000; Booij et al. 2002; Ellenbogen et al. 1996) and subjects with certain genetic variations in the 5HT transporter gene (Roiser et al. 2006; Finger et al. 2007). Fusar-Poli et al. (2006) furthermore suggest that the effects observed after ATD might not be mediated solely through a 5-HT-related mechanism, but rather indirectly via compensatory mechanisms of other transmitter systems (see also Praschak-Rieder et al. 2004). One candidate for this is dopamine (DA). Although direct evidence for ATD-induced effects on other transmitter systems, including DA, is lacking, there is compelling evidence that 5-HT can directly regulate dopaminergic activity and, consequently, function (for a current review, see Alex and Pehek 2007).

On the other hand, evidence for the effect of ATD on the actual neuronal release of 5-HT in the brain is sparse and, in most cases, indirect. Human studies are limited in their measurement to imaging studies of central 5-HT synthesis (Nishizawa et al. 1997), 5-HT receptor occupation (Udo de Haes et al. 2002; Praschak-Rieder et al. 2004) and cerebrovascular fluid measurement of tryptophan and 5-HT metabolism (Carpenter et al. 1998). Although these studies partially confirm reduced synthesis of 5-HT and do report lowered levels of the metabolite of 5-HT in cerebrospinal fluid, evidence for reduced release of 5-HT is absent.

A number of rodent studies, in general employing the same method of ATD, suggest that in addition to reduced tryptophan availability and reduced 5-HT synthesis, the actual synaptic release of 5-HT is lowered. Evidence for the assumption that ATD does in fact lower 5-HT release is, however, inconclusive. Microdialysis studies have been able to show reduced extracellular 5-HT after ATD only in the presence of a selective serotonin reuptake inhibitor (SSRI; Fadda et al. 2000b; Bel and Artigas 1996; Stancampiano et al. 1997), while there are no reports that show decreased or unaffected 5-HT efflux in animals that are not treated with SSRIs. This is an important observation, as non-physiological blockade of serotonin reuptake can interfere with normal transmitter release, making a clear-cut interpretation of the data difficult. Furthermore, Marco and Meek (1979) show that SSRI treatment in rats can reduce synthesis, which, in turn, could augment the depletion of 5-HT pools induced by ATD (see also Carlsson and Lindqvist 1978; Moret and Briley 1997; Fuxe et al. 1982 and Yamane et al. 2001).

In line with the evidence for prefrontal mediated effects of ATD mentioned earlier, we examined the effect of ATD on extracellular concentrations of both 5-HT and DA in the PFC in spontaneously active, and behaviourally stimulated, animals. We aimed to investigate whether successful lowering of blood plasma tryptophan concentration with ATD leads to a reduction of medial prefrontal 5-HT efflux in the absence of a serotonergic reuptake blockade.

\section{Materials and methods}

All experiments were approved by the Animal Experimentation Committee of the Royal Netherlands Academy of Arts and Sciences and were carried out in agreement with Dutch Laws (Wet op de Dierproeven, 1996) and European regulations (Guideline 86/609/EEC).

\section{Subjects}

Subjects were 20 male outbred Wistar rats (Harlan/CPB, Horst, The Netherlands) weighing 175-200 g at arrival. Upon arrival, the animals were socially housed in groups of four in standard type IV macrolon cages where they were kept under a reversed day/night cycle (dimmed red light from 7 A.M. until 7 P.M., white light from 7 P.M. until 7 A.M.) for the duration of the experiment. After surgery and during experimental procedures, the animals were kept in individual cages $(25 \times 25 \times 35 \mathrm{~cm})$.

\section{Surgery}

Two weeks after arrival, the animals were subjected to surgery for placement of a jugular vein catheter and implantation of bilateral microdialysis probes. The weight of the animals at time of the surgery was $297-332 \mathrm{~g}$. Rats were anesthetised with intramuscular Hypnorm $(0.24 \mathrm{mg} / \mathrm{kg}$ fentanyl citrate and $7.5 \mathrm{mg} / \mathrm{kg}$ fluanisone, Janssen); subcutaneous Dormicum $(0.75 \mathrm{mg} / \mathrm{kg}$ midazolam, Roche) was given for muscle relaxation. A silicon catheter was placed in the right jugular vein to allow for blood sampling, as described by Steffens (1969). For the subsequent implantation of the microdialysis probes, the animals were 
mounted in a stereotactic frame with the toothbar set at $-2.5 \mathrm{~mm}$. Bilateral probes were then placed in the medial PFC at an angle of $12^{\circ}(A+30 L \pm 18 ; V-55)$. Both microdialysis probes and jugular vein cannula were secured to the scull with dental cement and two cranial screws. Postoperative pain reduction was achieved with Temgesic $(0.10 \mathrm{mg} / \mathrm{kg}$ buprenorphine, Schering-Plough), $0.03 \mathrm{ml} / 100 \mathrm{~g}$ b.w. s.c approximately $2 \mathrm{~h}$ after surgery. After surgery, the animals returned to individual cages for the remainder of the experiments.

\section{Experimental procedure}

Approximately 1 week after surgery, the animals were assigned to either the experimental or control condition, with the body weight of the animals matched between groups. Fourteen hours before the experiment, food was removed from the home cages. On the day of the measurement, the animals were transferred to the experimentation room where they were kept in cages that contained their own bedding material. For the duration of the experiment, the animals were connected to the microdialysis tubing and blood sampling lines, which were attached to a swivel and counterbalanced beam out of reach of the animals. In this way, the animals were unrestricted in their movement, and the collection of blood samples could be achieved without handling the animals.

The collection of hourly blood samples started as soon as stable efflux of DA and 5-HT was observed (see below), which was approximately $2 \mathrm{~h}$ after connection. A first administration of the diet (see below) followed the initial blood sampling; a second administration was given $90 \mathrm{~min}$ after the first. Two and a half hours after the first diet administration, the rats were subjected to $20 \mathrm{~min}$ of 'novelty' stimulation.

During this period, the animals were given access to an identically shaped cage, filled with new bedding material, by means of an opaque sliding door connecting the measurement cage with the 'novelty' cage.

Optical movement detectors, connected to a PC running locally written software, were placed on top of the cages to detect possible changes in locomotor behaviour due to diet administration.

All animals were tested individually on separate days. A radio played to mask background noise and minimise interference from experimental procedures.

\section{Treatment}

The experimental rats (TRP minus group) were treated orally with a protein-carbohydrate mixture lacking tryptophan (TRP; $4.0 \mathrm{~g} / \mathrm{kg}$ Solugel PTM and $2.0 \mathrm{~g} / \mathrm{kg}$ Maltodextrine) in a volume of $10 \mathrm{ml} / \mathrm{kg}$ (see Table 1). Two diet administrations were given, spaced $90 \mathrm{~min}$ apart. Control animals received the same mixture with added TRP $(0.28 \%$ TRP of total protein). The exact composition of the mixture and the procedure for administration is identical to that described in Lieben et al. (2004a). To minimise stress, the rats were daily handled and habituated to oral injections with normal tap water $(10 \mathrm{ml} / \mathrm{kg})$. To minimise TRP intake through the normal rat chow, food was removed from the home cages $14 \mathrm{~h}$ before the start of the experiment. Water, however, remained freely available during this period.

Blood sampling and quantification of TRP content

On the experimental day, hourly blood samples were taken via the jugular vein catheter and analysed for TRP content. We collected six consecutive blood samples during the experiment. The first sample was taken after a stable microdialysis baseline was established and just before the first diet administration was given. Before the start of the experiment, the rats were habituated to blood sampling to minimise stress (i.e. a syringe was attached to the catheter and blood was withdrawn and immediately returned).

Table 1 Composition of the nutritional mixture and determination of the amino acids content of the gelatin-based protein

\begin{tabular}{lc}
\hline Mixture & Values \\
\hline Protein (Solugel $\mathrm{P}^{\circledR}$ ) in $100 \mathrm{ml}$ tap water & $\mathbf{1 0 0}$ \\
Aspartic acid + asparagine & 5.2 \\
Glutamic acid + glutamine & 9.3 \\
Hydroxyproline & 12.1 \\
Serine & 3.1 \\
Glycine & 22.5 \\
Histidine & 0.5 \\
Arginine & 8.8 \\
Threonine & 1.1 \\
Alanine & 9.3 \\
Proline & 13.3 \\
Tyrosine & 0.4 \\
Valine & 2.1 \\
Methionine & 0.6 \\
Cysteine & 0.2 \\
Isoleucine & 1.4 \\
Leucine & 3.0 \\
Hydroxylysine & 1.4 \\
Phenylalanine & 1.9 \\
Tryptophan & 0.1 \\
Lysine & 3.6 \\
Carbohydrate (Malthodextrine) in 80 ml tap water & $\mathbf{5 0}$ \\
KCl & $\mathbf{0 . 0 9 4}$ \\
CaCl ${ }_{2}$ 2 $\mathrm{H}_{2} \mathrm{O}$ & $\mathbf{2 . 3 2}$ \\
L-Tryptophan (Tryp minus group) & $\mathbf{0}$ \\
L-Tryptophan (control group) & $\mathbf{0 . 2 8}$ \\
\hline & \\
\hline &
\end{tabular}

The composition of the administered mixture used in the current experiment is depicted in bold. The amino acid content $(\%)$ of the protein was obtained from PB Gelatins, Tessenderlo, Belgium. 
Blood samples $(200 \mu \mathrm{l})$ were collected in heparin-filled tubes and deproteinised with 5-sulfosalicylic acid (5\%). After centrifuging $(15 \mathrm{~min}$ at $3,220 \times \mathrm{g})$, the samples were stored at $-80^{\circ} \mathrm{C}$ until analysis.

After completion of the experiment, the plasma samples were thawed at $4^{\circ} \mathrm{C}$, and $20 \mu \mathrm{l}$ supernatants were transferred to a high-performance liquid chromatograph (HPLC) for analysis (Waters 600E pump and Waters 717 plus autosampler, Waters Chromatography b.v., Netherlands; Jasco FP-920 intelligent fluorescence detector, Jasco, Benelux B.V., Netherlands and Shimadzu Class-vp ${ }^{\mathrm{TM}}$ software v.5.03 Shimadzu Duisburg, Germany).

The mobile phase consisted of $0.06 \mathrm{~mol} / 1$ sodium acetate, $9 \mathrm{mmol} / 1$ citric acid, $0.37 \mathrm{mmol} / 1$ sodium 1 -heptane sulfonate (HSA) and $12.5 \%$ methanol in milliQ water. The flow rate was kept constant at $1.0 \mathrm{ml} / \mathrm{min}$. Separation of TRP from other components was achieved with a Supelcosil column (LC-18-DB $25 \mathrm{~cm} \times 4.6 \mathrm{~mm} \times 5 \mu \mathrm{m}$ ), with a 2 -cm guardcolumn of the same material (Supelco Superguard ${ }^{\mathrm{TM}}$, Supelco USA), at a constant temperature of $40^{\circ} \mathrm{C}$. Quantification was achieved by means of fluorescence detection, with the excitation wavelength set at $335 \mathrm{~nm}$ and an emission wavelength of $440 \mathrm{~nm}$. TRP content was measured against a calibration curve of an external TRP standard.

Microdialysis probes and measurements

Concentric dialysis probes, manufactured and routinely used in this laboratory (Feenstra and Botterblom 1996), were constructed from fused silica (i.d. $0.075 \mathrm{~mm}$ ) protected by $25-\mathrm{G}$ needles as inlet and outlet. A Hospal membrane (o.d. $0.32 \mathrm{~mm}$, i.d. $0.24 \mathrm{~mm}$ ) with $3-\mathrm{mm}$ exposed length was fitted for these experiments.

A week after surgery (Feenstra et al. 2000), the animals were transferred to the test room where the dialysis probes were connected to PEEK (polyetheretherketone)-tubing (o.d. $0.51 \mathrm{~mm}$; i.d. $0.13 \mathrm{~mm}$; Aurora Borealis, Netherlands) attached to a dual-channel swivel (Pronexus, Skärholmen, Sweden). A Univentor 801 microinfusion syringe pump delivered a ringer solution $\left(145 \mathrm{mmol} / / \mathrm{NaCl}, 1.2 \mathrm{mmol} / 1 \mathrm{CaCl}_{2}\right.$, $2.7 \mathrm{mmol} / 1 \mathrm{KCl}, 1.0 \mathrm{mmol} / 1 \mathrm{MgCl}_{2}$ ) at a flow rate of $1.3 \mu \mathrm{l} / \mathrm{min}$. Dialysate was directly introduced into the electrically actuated HPLC injector (Valco, VICI, C6W), and $50 \mu \mathrm{l}$ was injected every $15 \mathrm{~min}$. DA and 5-HT were separated on a Supelcosil column (LC-18-DB $25 \mathrm{~cm} \times$ $4.6 \mathrm{~mm} \times 5 \mu \mathrm{m})$ and detected by means of an ANTEC VT03 electrochemical flowcell (50- $\mu \mathrm{m}$ spacer) set at $+0.65 \mathrm{~V}$ against a $\mathrm{Ag} / \mathrm{AgCl}$ reference electrode.

The mobile phase consisted of $0.06 \mathrm{~mol} / 1$ sodium acetate, $9 \mathrm{mmol} / 1$ citric acid, $0.37 \mathrm{mmol} / 1$ HSA and $12.5 \%$ methanol in milliQ water. The flow rate was kept constant at $1.0 \mathrm{ml} / \mathrm{min}$; a pulse damper (ANTEC, Leyden) was placed with the column inside the DECADE detector unit (ANTEC) and kept at a constant temperature of $40^{\circ} \mathrm{C}$.

The DECADE unit was programmed to automatically make an injection every 15 min and simultaneously start registration of the detector output. 5-HT and DA content was measured against a calibration curve of an external standard using Shimadzu Class-VPTM software (Shimadzu, v.5.03). The detection limit (ratio signal to noise $=2$ ) was $0.15 \mathrm{pg}$ of 5-HT and DA injected onto the column.

Drugs and chemicals

The Gelatine hydrolysate (Solugel PTM) was obtained from PB Gelatins (Tessenderlo, Belgium). Glucodry 200 was obtained from the Amylumgroup (Koog aan de Zaan, the Netherlands). Potassium chloride ( $\mathrm{KCl})$, calciumchloridedihydrate $\left(\mathrm{CaCl}_{2} \cdot 2 \mathrm{H}_{2} \mathrm{O}\right)$, sodium chloride $(\mathrm{NaCl})$, sodium 1-heptane sulfonate (HSA), methanol and tryptophan were obtained from Sigma-Aldrich Chemie, Germany. 5-Sulfosalicyclic acid dehydrate and magnesium chloride hexahydrate $\left(\mathrm{MgCl}_{2} \cdot 6 \mathrm{H}_{2} \mathrm{O}\right)$ were obtained from Merck Schuchhardt. Sodium acetate and citric acid were purchased at Janssen Chimica, Geel, Belgium

Histological examination

After completion of the experiments, the rats were humanely killed by inhalation of a mixture of $\mathrm{CO}_{2} / \mathrm{O}_{2}$ (70/30) followed by $100 \% \mathrm{CO}_{2}$. The brains were rapidly taken out of the skull and frozen at $-20^{\circ} \mathrm{C}$. Coronal $(20 \mu \mathrm{m})$ sections were cut on a cryostat and stained with thionine for examination with the microscope for the precise location of the microdialysis probes.

\section{Data analysis}

Changes in extracellular concentration of DA and 5-HT were calculated as deviations from the baseline defined as the last two samples preceding the first diet administration. Changes in plasma levels of TRP were compared to the first sample preceding diet administration. 'Movement-counts', in arbitrary units, registered by the optical movement detector were taken as measure for possible changes in activity. All data were analysed using a repeated measures analysis of variance (ANOVA) with time as within-factor and group/treatment as between-factor. If indicated by the Mauchly's test of sphericity, the number of degrees of freedom was adjusted by a Huynh-Feldt correction.

If indicated by an ANOVA group or interaction effect, subsequent evaluation of the effects of the treatment on individual samples was done by the Student NewmanKeuls test with repeated measures in which all samples are mutually compared. The level of significance was $p<0.05$. 
The effect of novelty exposure on 5-HT and DA release and general activity during the measurement was assessed by recalculation of a baseline from the two samples before novelty exposure. The data were then analysed as described above. All data are presented as means \pm SEM.

\section{Results}

Histological examination and animal exclusion Histological sections were examined for placement of the microdialysis probes. Data from rats with incorrectly placed probes were not included in the analysis. After exclusion, both the control group and the TRP minus group included eight animals.

Plasma concentrations Figure 1 shows the change of plasma tryptophan concentrations for both the control and treated group. Due to blockade of several jugular vein cannulas, the control group included seven and the TRP minus group, five animals. Average plasma concentrations $(\mu \mathrm{g} / \mathrm{ml})$ of tryptophan for the initial baseline samples were $18.80 \pm 11.92$ for the control group and $21.51 \pm 15.64$ for the TRP minus group.

A repeated measures ANOVA with group (TRP minus/ control) as between-subjects factor and time as withinsubjects factor resulted in a main effect of time $\left[F_{(4.45,44.50)}=\right.$ $3.07 p<0.03]$ and group $\left[F_{(1,10)}=38.76, p<0.0005\right]$ as well as a group/time interaction $\left[F_{(4.45,10)}=8.09, p<0.0005\right]$. An additional $t$ test revealed a significant reduction of the TRP minus group compared to the control group (time point $3: t=$ $6.00, p<0.0005$; time point $4: t=7.66, p<0.0005$; time point

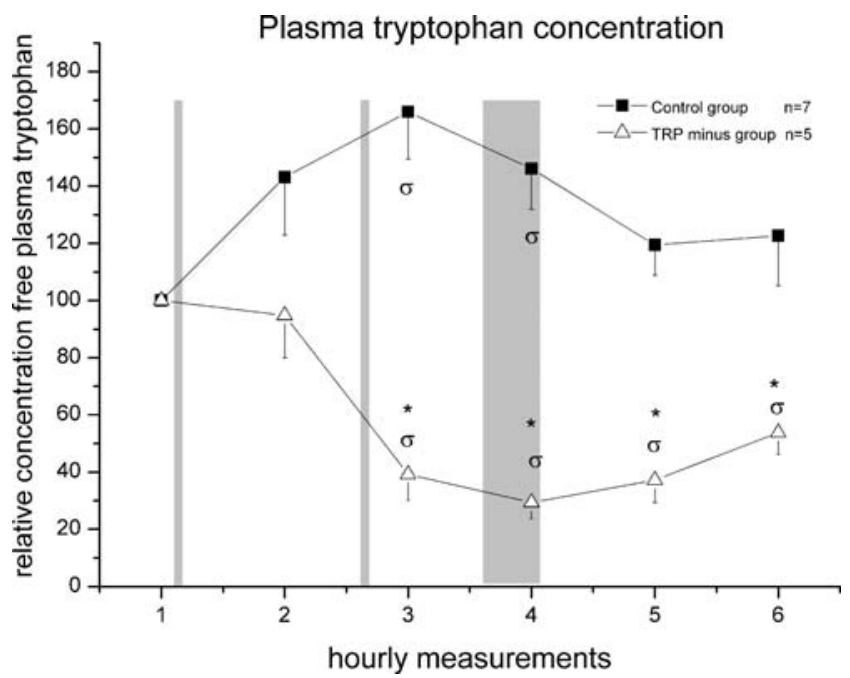

Fig. 1 Plasma tryptophan concentration. Relative concentration (mean $\pm \mathrm{SEM}$ ) of tryptophan in plasma compared to baseline. Open triangles correspond to the TRP minus group; closed squares correspond to the control group. The vertical grey bars correspond to, respectively, first diet administration, second diet administration and novelty exposure. Asterisk indicates a significant difference between the two groups, $p<0.05$; sigma indicates a significant difference compared to the baseline value, $p<0.05$
5: $t=5.76, p<0.0005$; time point $6: t=3.15, p=0.01$; Fig. 1 ). In contrast to the control group that showed an initial increase in plasma tryptophan (up to $167 \%$ ) and returned to baseline values $\left[F_{(5,30)}=3.50, p<0.02\right]$, the TRP minus group showed a persistent decrease in plasma tryptophan after the second administration, with a minimum of $29 \%$ of baseline $2 \mathrm{~h}$ after the first diet administration $\left[F_{(2.51,10.06)}=15.26, p=0.001\right]$. A simple contrast ANOVA for the control group revealed that time points 3 and 4 were significantly different from baseline; for the TRP minus, time points $3,4,5$ and 6 were different from baseline.

\section{Microdialysis}

Microdialysis of 5-HT Figure 2a shows the relative change, compared to two baseline samples, in 5-HT efflux over the entire day. An ANOVA with repeated measures revealed no significant group $\left[F_{(1,14)}=0.57, p>0.4\right]$, time $\left[F_{(13.49,188.78)}=\right.$ $1.19, p>0.2]$ or interaction effect $\left[F_{(13.49,14)}=0.97, p>0.4\right]$. Average transmitter concentrations $(\mathrm{pg} / 50 \mu \mathrm{l})$ of serotonin for the initial baseline samples were $1.41 \pm 0.27$ (mean \pm $\mathrm{SEM}$ ) for the control group and $1.48 \pm 0.23$ (mean \pm SEM) for the TRP minus group.

No significant differences between treated and control group were observed during novelty exposure when values were expressed relative to the original baseline or to a recalculated baseline just before the exposure.

Microdialysis of DA Figure $2 \mathrm{~b}$ shows the relative change, compared to two baseline samples, in DA efflux over the entire day. An ANOVA with repeated measures revealed a significant effect of time $\left[F_{(6.95,60.58)}=2.76, p<0.02\right]$, but not of group $\left[F_{(1,14)}=1.62, p>0.2\right]$ or of interaction $\left[F_{(8.14,14)}=0.98, p>0.4\right]$. Subsequent analysis of individual groups showed no time effect for either group.

Average extracellular transmitter concentrations $(\mathrm{pg} / 50 \mu \mathrm{l})$ of dopamine for the initial baseline samples were $0.64 \pm$ 0.15 (mean \pm SEM) for the control group and $0.72 \pm 0.16$ (mean $\pm \mathrm{SEM}$ ) for the TRP minus group.

No significant differences between treated and control group were observed during novelty exposure when values were expressed relative to the original baseline or to a recalculated baseline just before the exposure.

\section{Movement detection}

Figure $2 \mathrm{c}$ shows the average number of activity counts for both the control group and the TRP minus group. Average movement counts for the initial baseline samples were $123.59 \pm 17.71$ (mean \pm SEM) for the control group and $110.38 \pm 14.22$ (mean \pm SEM) for the TRP minus group. These data support the behavioural observation of sustained 
Efflux of 5-HT and DA and general activity

a

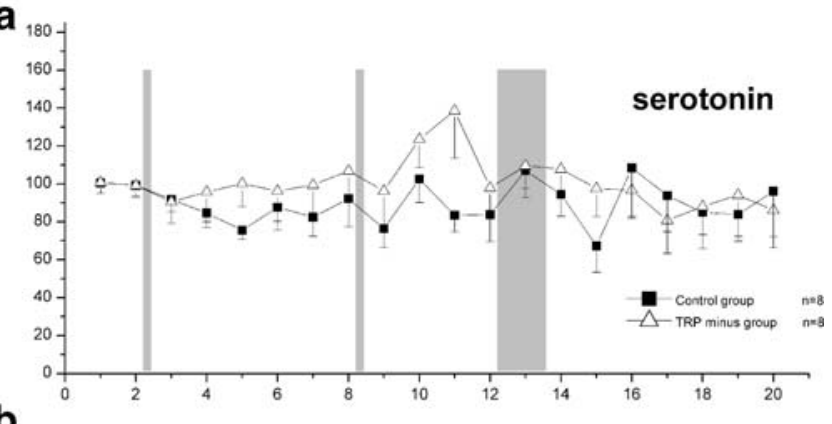

b

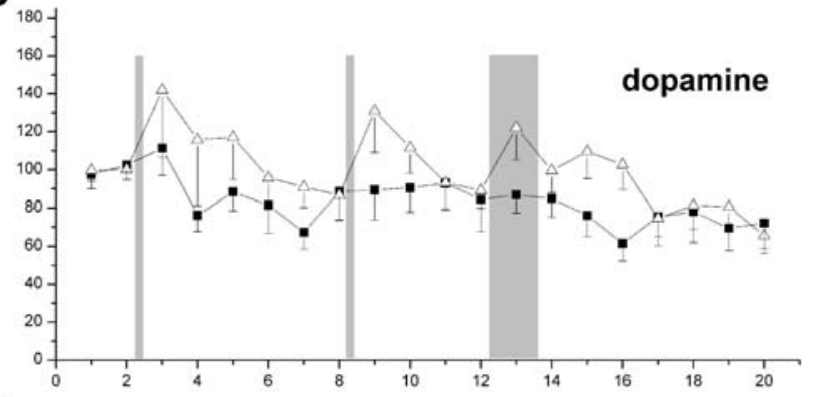

C

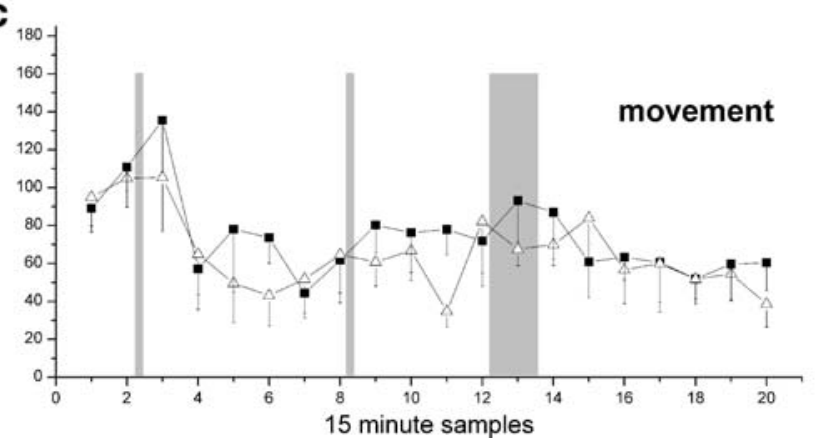

Fig. 2 Microdialysis of 5-HT and DA and general activity counts. Relative change in extracellular 5-HT and DA (mean \pm SEM) and movement compared to baseline. Open triangles correspond to the TRP minus group; closed squares correspond to the control group. a 5HT, b DA and c movement counts. The vertical grey bars correspond to, respectively, first diet administration, second diet administration and novelty exposure. No significant changes were observed

general activity throughout the measurements (e.g. grooming and explorative movement).

A repeated measures ANOVA revealed a significant effect of time over the entire day $\left[F_{(10.27,143.72)}=2.69, p<\right.$ $0.005]$. No group $\left[F_{(1,14)}=0.42, p>0.5\right]$ or interaction $\left[F_{(10.27,14)}=0.55, p>0.8\right]$ effect was observed.

The novelty stimulation did not cause any differential effect on overall activity.

\section{Discussion}

To gain insight into the relation between ATD and the release of serotonin $(5-\mathrm{HT})$ in the prefrontal cortex, we measured plasma levels of tryptophan and, simultaneously, PFC efflux of 5-HT and DA in animals that underwent
ATD. In line with current literature (Lieben et al. 2004a), ATD induced a rapid decline of free plasma tryptophan within $2 \mathrm{~h}$ of the initial administration that lasted throughout the experimental procedure. However, despite this reduction, efflux of prefrontal serotonin (5-HT), as measured in the medial PFC with microdialysis, was unaffected in these animals. In contrast to previous studies, these measurements, in behaviourally active animals, were performed in the absence of a serotonergic reuptake blocker. These results indicate that successful lowering of plasma tryptophan, to levels associated with behavioural effects, does not necessarily induce lowering of 5-HT efflux. Considering the widespread use of ATD as a method for studying the role of serotonin in behavioural and cognitive research, these findings are especially relevant.

The current experiment combined blood sampling through a chronic jugular vein catheter with online microdialysis measurements of 5-HT and DA. This combination of techniques was used to ensure that blood sampling did not hinder the animals in their behaviour or cause unwanted effects on transmitter release.

In line with current literature, we measured a rapid decrease of plasma tryptophan of more than $70 \%$. Although the possibility exists that a greater reduction of plasma tryptophan, which can be achieved with chronic tryptophan depletion (Fadda et al. 2000a), could have induced a reduction of 5-HT efflux, it would not explain the effects on behaviour and affect observed after tryptophan depletions of a magnitude similar to those observed in the current experiment (e.g. Riedel 2004; Lieben et al. 2004b; Delgado 2006). The 4.5-h time-window in which we measured is well within the period for which behavioural effects have been reported, reducing the likelihood that a decrease in 5HT efflux would have been observed had we measured for a longer period. Lack of sensitivity of the measurement equipment does not seem likely either; with the current detection limit, reductions of either transmitter would have been measurable.

The absence of a clear effect of novelty stimulation on either general activity or transmitter efflux might suggest that the animals were inactive. However, behavioural observation, as well as quantitative movement detection, indicates otherwise, showing that the animals were in fact active throughout the measurements (e.g. grooming, and explorative behaviour), although the active novelty exposure did not induce the expected increase in locomotor activity.

Literature data from both human and rodent studies show that ATD leads to lowering of plasma tryptophan (Biggio et al. 1974; Moja et al. 1989) and decreased synthesis (Gessa et al. 1974) and availability of central 5HT (Ashley and Curzon 1981; Fadda et al. 2000b; Lieben et al. 2004a), but, to date, it has not been convincingly shown that the ATD lowers efflux of 5-HT in the brain. The 
few rodent studies that do show reduced efflux after ATD either used chronic treatment with a tryptophan-deficient diet (Fadda et al. 2000b; Van der Stelt et al. 2004) or combined the measurements with drugs that prevent reuptake of 5-HT (Fadda et al. 2000b; Bel and Artigas 1996; Stancampiano et al. 1997; but see Bel and Artigas (1996) who observe an increase, rather than a decrease, of 5-HT efflux in the PFC after ATD in rats on free food). To the best of our knowledge, the current experiment is the first to report on the effect of ATD on prefrontal 5-HT efflux after overnight fasting in the absence of a reuptake blocker, an experimental design that parallels the behavioural studies in both rodents and human subjects. As pointed out in the "Introduction", this is especially important, as the addition of reuptake inhibition can lead to decreased 5-HT synthesis, and thus, augment the effect of ATD. In light of the behavioural effects observed after acute tryptophan depletion and the general notion that a reduction of synaptic 5-HT release underlies these effects, understanding the effect of ATD on 5-HT efflux, which is thought to reflect release, is essential.

Our data seem to suggest that successful tryptophan depletion does not alter 5-HT release. ATD, however, has convincingly shown to be an effective method to manipulate mood and induce cognitive/behavioural effects in both humans (Fusar-Poli et al. 2006; Riedel et al. 2002) and rodents (Fadda 2000; Riedel 2004). This apparent discrepancy will be discussed in the next section.

Although mood effects after ATD have been reported across populations of subjects, groups with vulnerability for 5-HT dysregulation (e.g. remitted depressed patients, women and people that show a genetic variation in the 5HT transporter gene) seem particularly sensitive to ATD (Delgado 2006; Booij et al. 2002; Moore et al. 2000; Neumeister 2003; Riedel et al. 2002; Roiser et al. 2006; Jans et al., 2007). It is argued that especially these groups are sensitive to ATD because they already show a reduced availability of central 5-HT that is further reduced by tryptophan depletion. In contrast to non-vulnerable subjects, these subpopulations will be less able to compensate for a temporary reduction in 5-HT synthesis and will experience a greater impact of ATD. Likewise, SSRI-treated animals will experience depletion of 5-HT stores (Marco and Meek 1979) and more readily show decreased 5-HT efflux after ATD than unmedicated rats. Measurements of indices of 5-HT release in response to ATD in 'vulnerable' rodents, like serotonin transporter knockout animals (Holmes et al. 2003), or females have not been performed.

In contrast to effects on mood, behavioural and cognitive effects are generally observed in a broader population that also includes healthy subjects (for a review, see Riedel et al. 2002) that do not show a particular sensitivity to 5-HT dysregulation.
The most parsimonious explanation that can unify those observations with the current data is that brain areas outside the medial PFC, which have not been measured in the present experiment, might mediate the behavioural effects. As the innervation of 5-HT in the brain is not uniform (McQuade and Sharp 1997; see for an overview Frazer and Hensler 1999) and some areas appear to be more sensitive to ATD than others (Lieben et al. 2004a; Fusar-Poli et al. 2006), the absence of 5-HT efflux reductions in the medial PFC might not reflect ATD-induced changes in other (prefrontal) areas.

However, this explanation seems to hold only partially at best. As mentioned in the "Introduction", ATD studies have implicated prefrontal 5-HT in various 'prefrontal' tasks, like reversal learning (Rogers et al. 1999; Finger et al. 2007) and intra-, extradimensional set shifting (Park et al. 1994), and shown ATD-induced changes in PFC activity (Rubia et al. 2005; Allen et al. 2006; Evers et al. 2005).

The possibility that other transmitter systems might mediate ATD effects (Fusar-Poli et al. 2006) was investigated by simultaneous measurements of DA. As we reported that DA efflux did not respond to the ATD, the current data cannot confirm this hypothesis, although other possible transmitters remain to be investigated.

While it is not possible to extrapolate these findings to brain areas outside the medial PFC, our present data show that an effective reduction of plasma tryptophan with ATD does not necessarily imply a similar reduction in 5-HT efflux. As ATD continues to be an important and widely used paradigm to study specific roles of 5-HT, it is important to clarify through which mechanism ATD exerts its effects and to what extent changes in 5-HT contribute to the functional effects of ATD.

Acknowledgements This study was funded by the ZonMW Topgrant 912-02-050 from the Dutch Organization for Scientific Research (NWO).

\section{References}

Alex KD, Pehek EA (2007) Pharmacologic mechanisms of serotonin regulation of dopamine neurotransmission. Pharmacol Ther 113:296-320

Allen PP, Cleare AJ, Lee F, Fusar-Poli P, Tunstall N, Fu, CHY, Brammer MJ, McGuire PK (2006) Effect of acute tryptophan depletion on pre-frontal engagement. Psychopharmacology (Berl) 187:486-497

Ashley VM, Curzon G (1981) Effects of long-term low dietary tryptophan intake on determinants of 5-hydroxytryptamine metabolism in the brains of young rats. J Neurochem 37:13851393

Bel N, Artigas F (1996) Reduction of serotonergic function in rat brain by tryptophan depletion: effects in control and fluvoxaminetreated rats. J Neurochem 67:669-676 
Biggio G, Fadda F, Fanni P, Tagliamonte A, Gessa GL (1974) Rapid depletion of serum tryptophan, brain tryptophan, serotonin and 5hydroxyindoleacetic acid by a tryptophan-free diet. Life Sci 14:1321-1329

Booij L, Van der Does W, Benkelfat C, Bremner JD, Cowen PJ, Fava M, Gillin C, Leyton M, Moore P, Smith KA, Van der Kloot WA (2002) Predictors of mood response to acute tryptophan depletion: a reanalysis. Neuropsychopharmacology 27:852-861

Booij L, Van der Does W, Riedel WJ (2003) Monoamine depletion in psychiatric and healthy populations: review. Mol Psychiatry 8:951-973

Bremner JD, Innis RB, Salomon RM, Staib LH, Ng CK, Miller HL, Bronen RA, Krystal JH, Duncan J, Rich D, Price LH, Malison R, Dey H, Soufer R, Charney DS (1997) Positron emission tomography measurement of cerebral metabolic correlates of tryptophan depletion-induced depressive relapse. Arch Gen Psychiatry 54:364-374

Carlsson A, Lindqvist M (1978) Effects of antidepressant agents on the synthesis of brain monoamines. J Neural Transm 43:73-91

Carpenter LL, Anderson GM, Pelton GH, Gudin JA, Kirwin PD, Price LH, Heninger GR, McDougle CJ (1998) Tryptophan depletion during continuous CSF sampling in healthy human subjects. Neuropsychopharmacology 19:26-35

Delgado PL (2006) Monoamine depletion studies: implications for antidepressant discontinuation syndrome. J Clin Psychiatry 67 (Suppl 4):22-26

Ellenbogen MA, Young SN, Dean P, Palmour RM, Benkelfat C (1996) Mood response to acute tryptophan depletion in healthy volunteers: sex differences and temporal stability. Neuropsychopharmacology $15: 465-474$

Evers EAT, Cools R, Clark L, Van der Veen FM, Jolles J, Sahakian BJ, Robbins TW (2005) Serotonergic modulation of prefrontal cortex during negative feedback in probabilistic reversal learning. Neuropsychopharmacology 30:1138-1147

Fadda F (2000) Tryptophan-free diets: a physiological tool to study brain serotonin function. News Physiol Sci 15:260-264

Fadda F, Cocco S, Rossetti ZL, Melis G, Stancampiano R (2000a) A tryptophan-free diet markedly reduces frontocortical 5-HT release, but fails to modify ethanol preference in alcoholpreferring (sP) and non-preferring (sNP) rats. Behav Brain Res 108:127-132

Fadda F, Cocco S, Stancampiano R (2000b) A physiological method to selectively decrease brain serotonin release. Brain Res Brain Res Protoc 5:219-222

Feenstra MGP, Botterblom MHA (1996) Rapid sampling of extracellular dopamine in the rat prefrontal cortex during food consumption, handling and exposure to novelty. Brain Res 742:17-24

Feenstra MGP, Botterblom MHA, Mastenbroek S (2000) Dopamine and noradrenaline efflux in the prefrontal cortex in the light and dark period: effects of novelty and handling and comparison to the nucleus accumbens. Neuroscience 100:741-748

Finger EC, Marsh AA, Buzas B, Kamel N, Rhodes R, Vythilingham M, Pine DS, Goldman D, Blair JR (2007) The impact of tryptophan depletion and 5-HTTLPR genotype on passive avoidance and response reversal instrumental learning tasks. Neuropsychopharmacology 32:206-215

Frazer A, Hensler JG (1999) Serotonin. In: Siegel GJ, Agranoff BW, Albers RW, Fisher SK, Uhler MD (eds) Basic neurochemistry; molecular, cellular and medical aspects, 6th edn. LippincottRaven Publishers, Philadelphia, pp 264-292

Fusar-Poli P, Allen P, McGuire P, Placentino A, Cortesi M, Perez J (2006) Neuroimaging and electrophysiological studies of the effects of acute tryptophan depletion: a systematic review of the literature. Psychopharmacology (Berl) 188:131-143

Fuxe K, Ogren SO, Agnati LF, Andersson K, Eneroth P (1982) Effects of subchronic antidepressant drug treatment on central serotonergic mechanisms in the male rat. Adv Biochem Psychopharmacol 31:91-107

Gessa GL, Biggio G, Fadda F, Corsini GU, Tagliamonte A (1974) Effect of the oral administration of tryptophan-free amino acid mixtures on serum tryptophan, brain tryptophan and serotonin metabolism. J Neurochem 22:869-870

Holmes A, Murphy DL, Crawley JN (2003) Abnormal behavioral phenotypes of serotonin transporter knockout mice: parallels with human anxiety and depression. Biol Psychiatry 54:953-959

Jans LAW, Riedel WJ, Markus CR, Blokland A (2007) Serotonergic Vulnerability and depression: assumptions, experimental evidence and implications. Mol Psychiatry 12:522-543

Lieben CK, Blokland A, Westerink B, Deutz NE (2004a) Acute tryptophan and serotonin depletion using an optimized tryptophanfree protein-carbohydrate mixture in the adult rat. Neurochem Int 44:9-16

Lieben CK, Van Oorsouw K, Deutz NE, Blokland A (2004b) Acute tryptophan depletion induced by a gelatin-based mixture impairs object memory but not affective behavior and spatial learning in the rat. Behav Brain Res 151:53-64

Marco EJ, Meek JL (1979) The effects of antidepressants on serotonin turnover in discrete regions of rat brain. Naunyn Schmiedebergs Arch Pharmacol 306:75-79

McQuade R, Sharp T (1997) Functional mapping of dorsal and median raphe 5-hydroxytryptamine pathways in forebrain of the rat using microdialysis. J Neurochem 69:791-796

Moja EA, Cipolla P, Castoldi D, Tofanetti O (1989) Dose-response decrease in plasma tryptophan and in brain tryptophan and serotonin after tryptophan-free amino acid mixtures in rats. Life Sci 44:971-976

Moore P, Landolt HP, Seifritz E, Clark C, Bhatti T, Kelsoe J, Rapaport M, Gillin JC (2000) Clinical and physiological consequences of rapid tryptophan depletion. Neuropsychopharmacology 23: 601-622

Moret C, Briley M (1997) Ex vivo inhibitory effect of the 5-HT uptake blocker citalopram on 5-HT synthesis. J Neural Transm 104:147-160

Neumeister A (2003) Tryptophan depletion, serotonin, and depression: where do we stand? Psychopharmacol Bull 37:99-115

Neumeister A, Nugent AC, Waldeck T, Geraci M, Schwarz M, Bonne O, Bain EE, Luckenbaugh DA, Herscovitch P, Charney DS, Drevets WC (2004) Neural and behavioral responses to tryptophan depletion in unmedicated patients with remitted major depressive disorder and controls. Arch Gen Psychiatry 61: 765-773

Nishizawa S, Benkelfat C, Young SN, Leyton M, Mzengeza S, de Montigny C, Blier P, Diksic M (1997) Differences between males and females in rates of serotonin synthesis in human brain. Proc Natl Acad Sci USA 94:5308-5313

Park SB, Coull JT, McShane RH, Young AH, Sahakian BJ, Robbins TW, Cowen PJ (1994) Tryptophan depletion in normal volunteers produces selective impairments in learning and memory. Neuropharmacology 55:575-588

Praschak-Rieder N, Hussey D, Wilson AA, Carella A, Lee M, Dunn E, Willeit M, Bagby RM, Houle S, Meyer JH (2004) Tryptophan depletion and serotonin loss in selective serotonin reuptake inhibitor-treated depression: an [(18)F] MPPF positron emission tomography study. Biol Psychiatry 56:587-591

Riedel WJ (2004) Cognitive changes after acute tryptophan depletion: what can they tell us? Psychol Med 34:3-8

Riedel WJ, Klaassen T, Schmitt JA (2002) Tryptophan, mood, and cognitive function. Brain Behav Immun 16:581-589

Rogers RD, Blackshaw AJ, Middleton HC, Matthews K, Hawtin K, Crowley C, Hopwood A, Wallace C, Deakin JF, Sahakian BJ, Robbins TW (1999) Tryptophan depletion impairs stimulusreward learning while methylphenidate disrupts attentional 
control in healthy young adults: implications for the monoaminergic basis of impulsive behaviour. Psychopharmacology (Berl) 146:482-491

Roiser JP, Blackwell AD, Cools R, Clark L, Rubinsztein DC, Robbins TW, Sahakian BJ (2006) Serotonin transporter polymorphism mediates vulnerability to loss of incentive motivation following acute tryptophan depletion. Neuropsychopharmacology 31:2264-2272

Rubia K, Lee F, Cleare AJ, Tunstall N, Fu CHY, Brammer M, McGuire P (2005) Trypophan depletion reduces right inferior prefrontal activation during response inhibition in fast, eventrelated fMRI. Psychopharmacology (Berl) 179:791-803

Schmitt JA, Jorissen BL, Sobczak S, van Boxtel MP, Hogervorst E, Deutz NE, Riedel WJ (2000) Tryptophan depletion impairs memory consolidation but improves focussed attention in healthy young volunteers. J Psychopharmacol 14:21-29

Stancampiano R, Melis F, Sarais L, Cocco S, Cugusi C, Fadda F (1997) Acute administration of a tryptophan-free amino acid mixture decreases 5-HT release in rat hippocampus in vivo. Am J Physiol 272:R991-R994
Steffens AB (1969) A method for frequent sampling of blood and continuous infusion of fluids in the rat without disturbing the animal. Physiol Behav 4:833-836

Udo de Haes JI, Bosker FJ, Van Waarde A, Pruim J, Willemsen AT, Vaalburg W, Den Boer JA (2002) 5-HT(1A) receptor imaging in the human brain: effect of tryptophan depletion and infusion on [(18)F]MPPF binding. Synapse 46:108-115

Van der Stelt HM, Broersen LM, Olivier B, Westenberg HGM (2004) Effects of dietary tryptophan variations on extracellular serotonin in the dorsal hippocampus of rats. Psychopharmacology (Berl) 172:137-144

Yamane F, Okazawa H, Blier P, Diksic M (2001) Reduction in serotonin synthesis following acute and chronic treatments with paroxetine, a selective serotonin reuptake inhibitor, in rat brain: an autoradiographic study with alpha-[14C]methyl-L-tryptophan (2). Biochem Pharmacol 62:1481-1489

Young SN, Leyton M (2002) The role of serotonin in human mood and social interaction. Insight from altered tryptophan levels. Pharmacol Biochem Behav 71:857-865 